DOI: $10.20472 / E S .2020 .9 .1 .003$

\title{
RECIPROCITY IN STUDENT GROUPS: EXPERIMENTAL EVIDENCE FROM GREECE
}

\author{
ANTONIOS AVGERIS, PANAGIOTA SERGAKI, ACHILLEAS \\ KONTOGEORGOS, ANTONIOS TIGANIS
}

\begin{abstract}
:
Every correlated theory on the decision-making process takes for granted that individuals have a self-seeking behaviour in a self-regulating economic system. That means that under emergency and risk situations subjects make decisions following the above theories, among fixed-various alternatives. Nevertheless, the results have emerged from many investigations of recent years indicate a completely different approach on people's everyday decision making. Elements of human character such as justice, altruism and reciprocity seem to overlap the overall aspects of them. So, in this paper we aim to investigate the existence of reciprocity, or not, in student communities. In order to achieve this, two games of Game Theory list were adopted and applied in two different Greek Universities while Experimental Economics methods were used. These non-cooperative games (Ultimatum \& Dictator game) interacted as one in an uncertain environment. The results of the experimental process showed a reciprocal behaviour (positive or negative) among students with small differences between the two universities.
\end{abstract}

\section{Keywords:}

Decision-making, Dictator Game, Economic Behaviour, Experimental Economics, Greek Universities, Reciprocity, Ultimatum Game

JEL Classification: C72, C78, D64

\section{Authors:}

ANTONIOS AVGERIS, Aristotle University of Thessaloniki, Greece, Email: antoavge@agro.auth.gr PANAGIOTA SERGAKI, Aristotle University of Thessaloniki, Greece, Email: gsergaki@auth.gr ACHILLEAS KONTOGEORGOS, University of Patras, Greece, Email: akontoge@upatras.gr ANTONIOS TIGANIS, Aristotle University of Thessaloniki, Greece, Email: atiganis@agro.auth.gr

\section{Citation:}

ANTONIOS AVGERIS, PANAGIOTA SERGAKI, ACHILLEAS KONTOGEORGOS, ANTONIOS TIGANIS (2020). Reciprocity in Student Groups: Experimental Evidence from Greece. International Journal of Economic Sciences, Vol. IX(1), pp. 44-67., 10.20472/ES.2020.9.1.003 


\section{Introduction}

Both Theory of Expected Utility (E.U.T.) and Classical Decision Theory (C.D.T.), as well as, Rational Choice Theory (R.C.T.) signal the process by which individuals make decisions when they are in emergency situations (Bernoulli, 1954). Hence, making decisions includes a wide-fixed set of alternatives with a targeted goal in mind for each subject. For achieving this, there are three components that individuals have to follow. Options or courses of action, beliefs and expectancies of the options in achieving the goal and outcome expectancies (negative or positive) (Hastie and Dawes, 2010). At the same time, these theories treat people as beings who think and act perfectly rationally with an ultimate scope of utility maximizing from their final decision without taking into account the public good (Gutnik et al., 2006; Bicskei, Lankau and Bizer, 2016). Consequently, there are some economic models which have the rationalist and selfish agent as a basic assumption (Dufwenberg and Kirchsteiger, 2004). These models have unleashed or erased the influence of human emotions from the decision-making process by likening the decisionmaker as a perfectly rational subject, as a sprocket of a perfectly rational cognitive machine (Shen and Takahashi, 2013).

Although for many years these models had been a very representative tool of human behaviour, which even today has many supporters, yet a whole set of both empirical studies and experimental results proves that agents in many cases have a completely different behaviour than what Rational Theory predicts (Fehr and Gächter, 2000; Falk, Fehr and Fischbacher, 2008). Namely, these economic, based on rationality, models have been rejected by many scientists because they cannot represent, in many cases, the daily decision-making practices and experiences of individuals in real-time situations (Beach and Lipshitz, 1993). The consequence of this, is to be created a number of "unexpected utility" models in order to analyze, identify and present the emotional behaviour of the subjects (Panas, 2007). These models illustrate a completely different aspect of human behaviour as opposed to the above-mentioned theories. Concepts such as justice, philanthropy, altruism, and reciprocity prevail over opportunism, selfinterest and rationality. Also, these models enclose the idea of subjects' utility and material payoff sacrifice in order to provide fairness and reciprocity to their fellowmen (Rabin, 1993; Levine, 1998; Bolton and Ockenfels, 2000; Charness and Rabin, 2002).

In 1982 Amos Tversky gave the following definition about decision-making process:

"Decision making is a meeting ground for psychologists, economists, sociologists, organizational theorists, statisticians, philosophers and others. It is an exciting field, endowed with a deep formal theory, a rich technology, numerous intriguing observations of individuals and organizations, and a growing body of experiential results" (Tversky, 1982).

At the same time, according to Harrison (1993), decision-making is a complex system in which a plethora of scientific fields interact in a rapidly changing scientific world that is influenced by many disciplines.

\footnotetext{
* Corresponding Author: antoavge@agro.auth.gr
} 
Figure 1. The Rational Decision-Making Model

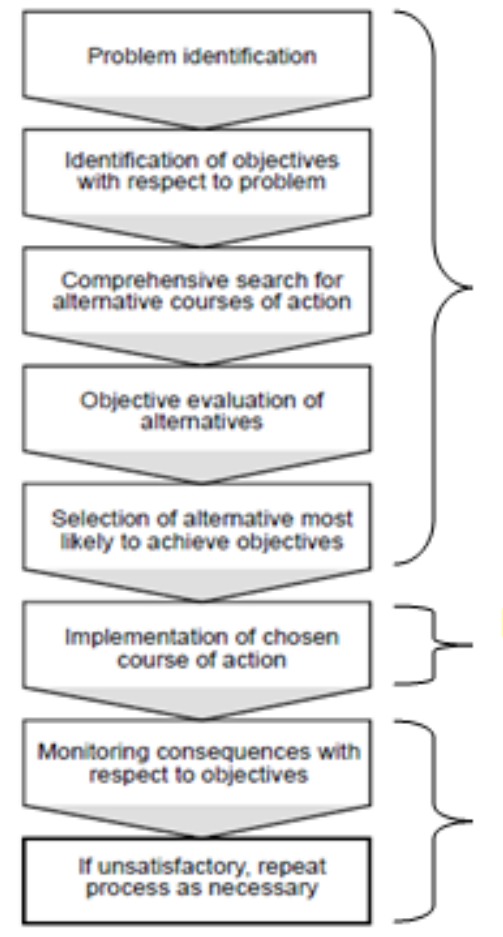

Source: Heracleous, 1994

\section{Options or courses of actions.}

Beliefs and expectancies of the options in achieving the

\section{Outcome expectancies \\ (negative or positive)goal}

As far as the economic field is concerned, even nowadays dominates the idea of selfish agent while absolute rationality reigns, i.e. the "economic man", in other words the "Homo Economicus". Homo Economicus is the economic being that represents the rational economic behaviour. Rational economic behaviour is the behaviour in which every subject decides and acts in such a way in order to maximize his satisfaction and his usefulness which is derived from his decision (Fehr, Kirchsteiger and Riedl, 1998). On the other side, the name of the second economic being which also belongs to the economic science is "Homo Reciprocans". Individuals are identified with this type of person because concepts such as selfishness, arrogance and materialism are automatically deflected from their behaviour. On the contrary, these subjects are possessed by altruism and self-denial while they care about the well-being of their fellow human beings. This is a clear tendency of reciprocity.

In 1986, the scientist and professor Robert Keohane (see Keohane, 1986) defined the concept of reciprocity as following:

"Reciprocity refers to exchanges of roughly equivalent values in which the actions of each party are contingent on the prior actions of the others in such a way that good is returned for good, and bad for bad." 
Indeed, reciprocity is presented, in the existing literature, as an action where the reply of the agents is based on the fair or unfair behaviour of their counterparts. People have a reciprocal behaviour when respond, on the one hand, with "good" way in a kind action, while on the other hand, with "bad" way in a hostile action (Rabin 1993; Dufwenberg and Kirchsteiger, 2004; Falk and Fischbacher, 2006; Fehr and Schmidt, 2006; Segal and Sobel, 2007; Stanca, Bruni and Corazzini, 2009). So, preferences and expectancies of the subjects regard not only the material gain, but also, the expected emotional effect resulting from the action he had previously done (Geanakoplos, Pearce and Stacchetti, 1989). Across the last decades, there is a wealth of behavioural data which confirms this emotional characteristic of people's daily decision-making process (Rietz et al., 2017). Hundreds of labor experiments, field projects as well as questionnaire surveys have carried out in order to clarify, identify and admit this behavioural disposition (McCabe, Rigdon and Smith, 2003; Falk and Fischbacher, 2006; Cox, Friedman and Gjerstad, 2007). Scientists from various disciplines, such as economists and behavioural economists, psychologists and behavioural psychologists, biologists and evolutionary biologists, sociologists, anthropologists, ethnologists, political scientists, etc. have already used the norm of reciprocity as a basic motivational key factor for their investigations (Trivers, 1971; Axelrod, 1984; Cosmides and Tooby, 1989; Nowak and Sigmund, 1998; Komorita and Parks, 1999; Wedekind and Milinski, 2000; de Waal and Berfer, 2000; Sobel, 2005; Bicskei, Lankau and Bizer, 2016).

In fact, Maximiano found out in her research paper that agents had developed a heterogeneous attitude in their predilections and choices as far as their economic decisions. The result of this is the appearance of a reciprocal behaviour by those involved in the experimental process while motivations such as personal interest and self-seeking were excluded (Maximiano, 2012). The element of reciprocal behaviour seems to dominate in some non-human subjects too. Specifically, Kay Prüfer and his team in 2012 ran an experiment between two species of chimpanzees (common and Bonobos species) and noted that the behavioural attitude of the chimpanzees did not diverge significantly from that of humans beings (Prüfer et al., 2012). Finally, reciprocity seems to be strong both in groups of people and collective communities. In every circumstance, members tend to trust, cooperate and help each other as well as reciprocate favours (Fehr and Falk, 1997; Avgeris, Kontogeorgos and Sergaki, 2017). Contrary to positive reciprocity, the negative aspect of the concept has emerged in many applied surveys and field investigations (Güth et al., 1982; Charness, 2004; Restubog et al., 2010; Wu et al., 2013; Kaltwasser et al., 2016).

As mentioned earlier, this work is intended, as a first step, to the identification of reciprocity in economic transactions between students, coming from two different Greek universities, while secondly, it seeks to compare the samples and observe differences, if any, between them. Other words, we aim to discover if students behave reciprocally or opportunistically and by which of two economic entities are matched with. 


\section{Scope and Research Objectives}

Classical economic and rational theories of the decision-making process (such as E.U.T., C.D.T. and R.C.T.) overlook any emotional attribute in human economic behaviour. This means that emotional states like altruism and reciprocity are automatically minimized and ignored. Nevertheless, various projects, from behavioural psychology and experimental economics as well as their results, have challenged the aforementioned established perception and support that emotions, in many cases, act as the main driver of human behaviour (Loewenstein and Lerner, 2003; Camerer, Loewenstein and Rabin, 2004). This leads to a rising question which constitutes a general concern:

"Why do rational models such as those used in economics and the classical decision-making theory not always accurately predict an individual's behaviour?"

Based on the previous question, this empirical paper aims to investigate and measure the level (high or low) and the kind (positive or negative) of reciprocity in two Greek universities. In particular, it is attempted to ascertain whether the students, who belong to a cluster (student group), behave according to the reciprocal norms (Homo Reciprocans) or follow the rules of rationality (Homo Economicus) with regard to their daily economic relations and decisions. Furthermore, the observation of the differences in the behavioral choices of the participants between the two universities is attempted.

Firstly, the empirical results that will be drawn from the comparison of the two experimental procedures are going to provide not only strong indications but also reliable evidence about the way in which individuals think and act, that is to say, as another Homo Economicus or Homo Reciprocans? At the next stage, the analysis will give an answer in the following question: Is there a significant difference in the two independent samples, and if so, why?

For achieving this aim, the authors adopted and used, in real-time situation, methods and systems of the experimental economics science and more particularly, two games of Game Theory. A detailed analysis of the methodology used is provided in the corresponding section.

\section{Data and Methodology}

\subsection{Data Collection}

This empirical work presents experimental evidence of a combined work carried out among undergraduate students in two different Greek universities. The duration of each experimental procedure was two months while the sample numbered $100(\mathrm{~N}=100)$ student-participants for each of the two experiments.

The first survey lasted from May till June 2015. It was designed and practiced at the University of Patras in the Department of Business Administration of Food and Agricultural Enterprises, which 
is housed in Agrinio, a city placed in Western Greece. The University of Patras is a regional university, with almost 34,000 students

The second part of this project (November - December of 2017) took place at Aristotle University of Thessaloniki and specifically in the Department of Agricultural Economics in Thessaloniki, in northern Greece. Aristotle University is the second largest university in Greece with more than 70,000 students.

\subsection{Methodology}

Data collection for both universities was carried out in two stages. At the first stage, participants were asked to fill a questionnaire about reciprocity (positive or negative), trust and cooperation that individuals have on each other on a daily basis (see Appendix). The scale used to grade the answers lies in the five-level scale (Likert scale) depending on how much they agree or disagree with the questionnaires' statements. The questionnaire (questions and structure) used was based on that of Perugini and his collaborators research (Perugini et al., 2003). The actual approach to measure reciprocity has been achieved by implementing two of the most well-known games in the Game Theory list. These games are the Ultimatum and the Dictator game and are often used in world literature. However, in this research these two games were combined and interacted as one, known as "Reciprocity Game" (see figure 2, below) (Avgeris, Kontogeorgos and Sergaki, 2018).

The innovation of this methodology lies in the direct interaction of the two players. That is, the final outcome of the game depends equally on the decisions of both players. The game consists of two rounds and each round is a separate sub-game with a sub-game perfect equilibrium involved in each. In the first round, the two players negotiated how to divide an amount. In the second round the last player (P2) of the previous round becomes the dictator, i.e. the first player (P1) of this round. The combination of these two games into one gives the advantage that each player is involved in two processes which would be impossible if the games were played separately. Because of the bargaining parties were unknown to each other in order for the process to achieve objectivity, the results depended only on the players' rational and emotional choices. In both samples the participants were given a hypothetical $10 €$ funding (not-real money) to run the experiment.

The beginning of the experimental process was done with the Ultimatum game which is an interdisciplinary game. It may belong to the field of experimental economics and game theory but its use is wide in a variety of research papers from different scientific fields (see Solnick and Schweitzer, 1999; Page and Nowak, 2001; Jensen, Call and Tomasello, 2007; Rauhut and Winter, 2010; Proctor, Brosnan and de Waal, 2013; Neumann et al., 2018). The first who created and consolidated the game in the bibliography was Güth and his colleagues in 1982 (see Güth, Schmittberger and Schwarze, 1982). The Ultimatum game is a two-counterpart bargaining game and it is usually played in one-shot version. The game begins when some quantity of money is shared by the experimenter to the first player (proposer). Now, the first player has to offer a part of the whole pie to the second player (responder). The second mover has the alternative of acceptance or rejection of the proposal is offered. If it is accepted, the money is divided according to the first player but if it is rejected, no-one gets something of the allocation. 
After that, the second player of the previous round (the responder) took the role of the dictator during the running of the Dictator game. This game is also widely used in the world literature where its references are found in many experiments from various disciplines. The first experimental scientists who established and used this game were Kahneman, Knetsch and Thaler in 1986. This game starts when the first mover (the dictator) chooses an allocation from the total endowment and gives it to the second player (the recipient). The difference here is that the last player does not have the power to negotiate with. So, the recipient just keeps the the part of the pie left by the first player (the dictator). Therefore, the presence of the second player does not affect at all the result of the experiment, since (s)he is limited to an elusive passive role.

Game theory literature states that the outcome and the result of a game is valid only if it is influenced by the interaction of the actions and decisions of at least two players. For the Dictator Game these requirements are not verified because the final outcome lies only in the decisions of one player, this of the dictator. Therefore, this game is widely accepted and used by the scientific community in many instances as an effective tool for examining rationalism and reciprocity in various aspects of everyday life of subjects (Oberholzer-Gee and Eichenberger, 2008; Krupka and Weber, 2013; Engle-Warnick and Mishagina, 2014).

Last but not least, is the fact of ethical issues, since the experimental process involve human interactions. In this part, authors have fully respected them. Each student participated in the experiment free from pressure and at his/her own will, since (s)he had been informed about the process and the main object-scope of this study. Even after the explanatory instructions, the participant retained the right to exclude him/her self from the experimental process, however, after the start, something similar was impossible since an even number of participants was required to complete it.

Figure 2. Tree Form of the "Reciprocity Game".

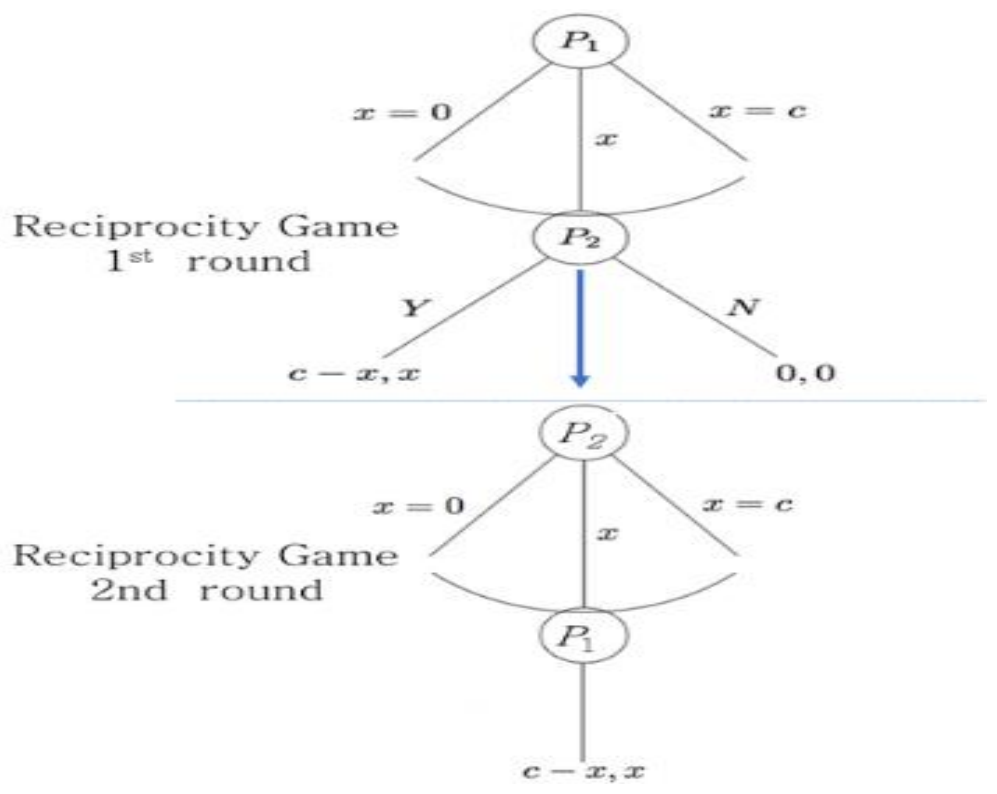

Source: Avgeris, Kontogeorgos and Sergaki, 2018 


\section{$4 \quad$ Results}

\subsection{Questionnaire Analysis}

\subsubsection{Analysis of the first part}

In the first part of the questionnaire the participants had to respond to a demographic type questions such as gender, age, year of registration at the university and their registration number. From the previous questions only, the gender will be analyzed by the authors because the rests could not influence the final conclusions. For example, as mentioned above, the experiment was conducted to undergraduate students so the age range as it implies was between 18-24 years old.

Regarding the first experimental procedure, in the University of Patras, the sample appears to be almost equally divided on the gender variable (male $48 \%$ and female $52 \%$ ). In Aristotle University is equally divided among genders. Consequently, a further analysis of the sample between the two Universities has no reason to be developed.

At the next stage the participants were asked to answer two dichotomous questions. These questions looked at the concepts of fairness (fair division) and injustice (unfair share). More specifically, the two questions were as follows:

- I believe it is fair when someone shares something equally between himself and some other person, and

- If someone did an unfair share against me then I would refuse to accept it.

Participants had to choose YES or NO to the specific question-suggestions as to whether they were consistent with their content or not. In both experimental samples the students responding affirmatively showed that they agree with the questions in a quite high percentage, surpassing even $80 \%$ in some answers (see Graph 1 and 2, below). 
Graph 1. The percentage of participants' responses to the first dichotomous question.

I believe it is fair when someone shares something equally between himself and some other person

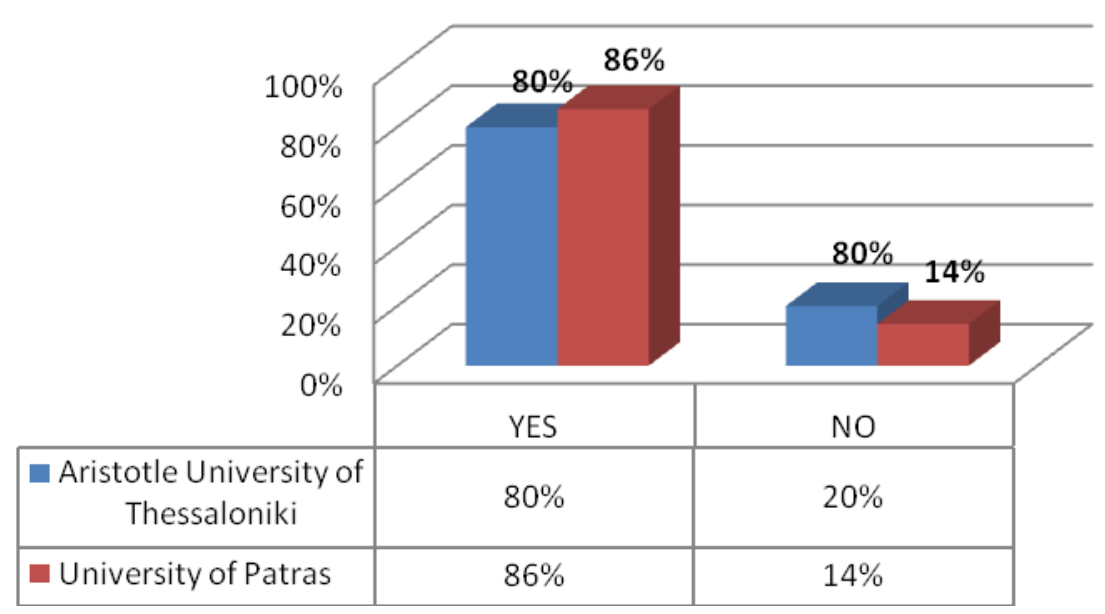

Source: Own calculations

Graph 2. The percentage of participants' responses to the second dichotomous question.

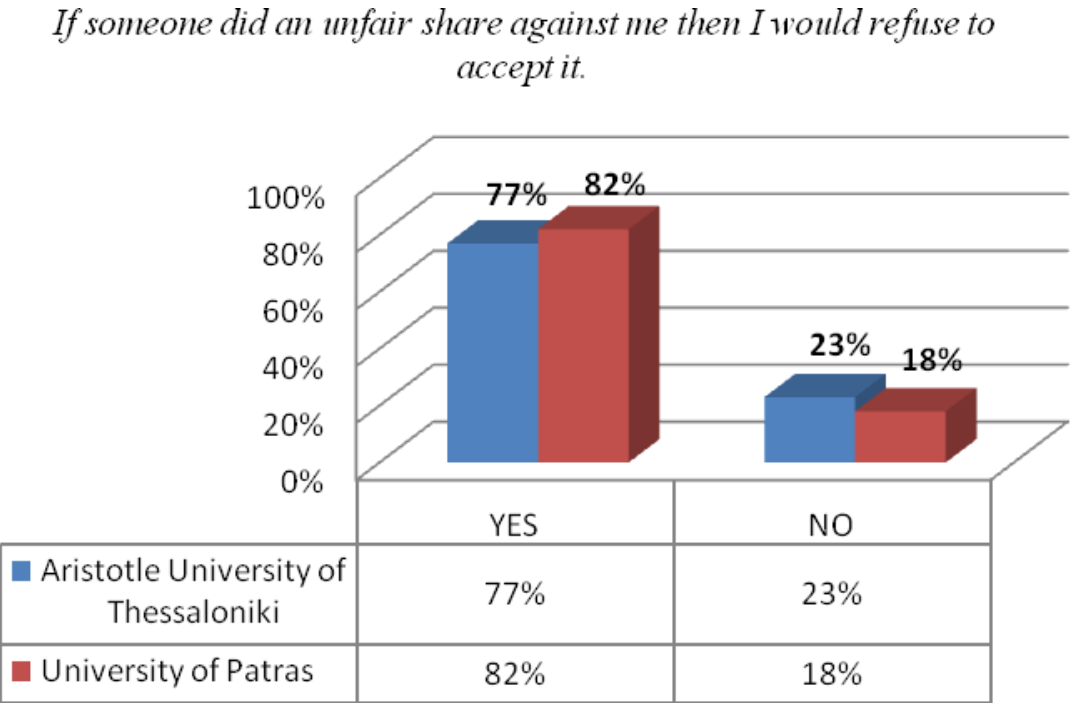

Source: Own calculations

The high concentration of positive responses to the first two dichotomous questions in the questionnaire highlights a tendency for fairness, equity and reciprocity. At the same time, signs of negative reciprocity are identified in the second question as individuals are willing to refuse an unfair division even if it is positive. According to the theory, people must accept a low offer 
because from the point of view of rational and economic interest something is better than nothing (Goodwin et al., 2013; Cartwright, 2014).

\subsubsection{Factor, reliability and parallel analysis}

In the second part of the questionnaire, there exist ten questions about reciprocity, cooperation and trust that people have in their everyday interactions. In this section, the respondents rated their responses on a five-level Likert scale depending on the degree of agreement or disagreement, i.e. $1=$ disagree strongly and $5=$ agree very much. In addition, in the same section there were 3 additional questions about the students' financial behaviour. The answers to these questions were also scored on a five-point scale where $1=$ Never and $5=$ Always.

In order to classify these questions into factors, a Principal Components Analysis (PCA) was performed on the total sample $(\mathrm{N}=200)$. The analysis showed the categorization of questions in four main factors that accounting $55.3 \%$ of the total variance. In particular, the first factor represented the questions of negative reciprocity and explained $20.12 \%$ of variance. The second factor named "willingness to give" and explained $13.88 \%$ of variance. The third of them was defined by questions of trust and explained $12.12 \%$ of variance while the last, the positive reciprocity explained $9.18 \%$ of variance. The eigenvalues of them are $2.62,1.80,1.58,1.19$ (see Table 1, below).

Table 1. Primary Principal Component Analysis for the questionnaire $(\mathrm{N}=200)$

\begin{tabular}{|c|c|c|c|c|}
\hline \multicolumn{5}{|c|}{ Loadings } \\
\hline Questions & $\begin{array}{l}\text { Negative } \\
\text { Reginrocity }\end{array}$ & Willingness to give & Trust & Positive Reciprocity \\
\hline Q1 ${ }^{1}$ & & & .677 & \\
\hline Q21 & & & & .502 \\
\hline $\mathrm{Q}^{1}{ }^{1}$ & & & & .493 \\
\hline Q41 & & & .750 & \\
\hline Q5 1 & & & .781 & \\
\hline $\mathrm{Q6}^{1}$ & & & & .740 \\
\hline Q7 ${ }^{1}$ & & & .618 & \\
\hline $\mathrm{Q8}^{1}$ & .757 & & & \\
\hline Q91 & .813 & & & \\
\hline Q101 & .814 & & & \\
\hline Q11 ${ }^{1}$ & & .765 & & \\
\hline Q12 ${ }^{1}$ & & .806 & & \\
\hline $\mathrm{Q13}^{1}$ & & .608 & & \\
\hline Eigenvalues & 2.62 & 1.80 & 1.58 & 1.19 \\
\hline$\%$ variance & $20.12 \%$ & $13.88 \%$ & $12.12 \%$ & $9.18 \%$ \\
\hline
\end{tabular}

${ }^{*}$ Extraction Method: Principal Component Analysis ${ }^{* *}$ Rotation Method: Oblimin with Kaiser Normalization

Source: Own calculations

${ }^{1}$ See Appendixat the end of the paper 
The next step in analyzing data is to test the reliability of the factors that were created. This analysis will be performed with the help of the reliability factor "Cronbach's Alpha". According to the results gathered, reliability was measured 0.78 for the first factor, 0.65 for the second factor and 0.76 for the third factor. However, the problem is attributed to the fourth factor where the reliability analysis produced a very low measurement. In particular, Cronbach's Alpha is equal to 0.152 . This is due to the fact that this factor explains just $9.18 \%$ of the total sample variance. In this case a parallel analysis is mandatory in order to decide exactly how many components should be extracted (see Table 2, below), while then a second-final Principal Components Analysis will be performed to extract the correct number of components.

Table 2. A run Matrix procedure of Parallel Analysis for Principal Components

\begin{tabular}{lccc}
\hline \multicolumn{3}{c}{ Random Data Eigenvalues } \\
Root & Means & Prcntyle & Eigenvalues \\
1,000000 & 1.441504 & 1.539496 & 2.62 \\
2,000000 & 1.329798 & 1.404316 & 1.80 \\
3,000000 & 1.243831 & 1.301830 & 1.58 \\
$\mathbf{4 , 0 0 0 0 0 0}$ & $\mathbf{1 . 1 7 4 7 8 6}$ & $\mathbf{1 . 2 2 1 1 6 5}$ & $\mathbf{1 . 1 9}$ \\
5,000000 & 1.104103 & 1.152714 & 1.01 \\
6,000000 & 1.041658 & 1.085479 & 0.91 \\
7,000000 & .986771 & 1.022614 & 0.77 \\
8,000000 & .926099 & .970725 & 0.75 \\
9,000000 & .869175 & .918866 & 0.63 \\
10,000000 & .811509 & .863737 & 0.55 \\
11,000000 & .753394 & .805789 & 0.50 \\
12,000000 & .694740 & .753050 & 0.37 \\
13,000000 & .622634 & .686244 & 0.32
\end{tabular}

${ }^{*}$ Ncases $=200$, Nvars $=13$, Ndatasets $=100$, Percent $=95$

Source: Own calculations

As it can be easily seen from the above table, the true number of components that is to be exported and used is 3 . This stems from the fourth row of the table where the value in the third column is greater than the value of corresponding eigenvalue $(1.22>1.19)$. This comparison leads us to look at the series above and the conclusion that the appropriate number of components that will be used in the following Principal Components Analysis is three. So, the whole procedure will be completed, and this paper is going to consist of three final factors (see Table 3). 
Table 3. Final Principal Component Analysis of the questionnaire $(\mathrm{N}=200)$

\begin{tabular}{|c|c|c|c|}
\hline \multicolumn{4}{|c|}{ Loadings } \\
\hline Questions & $\begin{array}{l}\text { Reciprocity } \\
\text { (Negative } \\
\text { or Positive) }\end{array}$ & Willingness to give & Trust \\
\hline Q1 & & & .563 \\
\hline Q2 & .315 & & \\
\hline Q3 & .506 & & \\
\hline Q4 & & & .647 \\
\hline Q5 & & & .727 \\
\hline Q6 & & & .457 \\
\hline Q7 & & & .494 \\
\hline Q8 & .754 & & \\
\hline Q9 & .812 & & \\
\hline Q10 & .812 & & \\
\hline Q11 & & .739 & \\
\hline Q12 & & .734 & \\
\hline Q13 & & .643 & \\
\hline Eigenvalues & 2.62 & 1.80 & 1.58 \\
\hline$\%$ variance & $20.12 \%$ & $13.88 \%$ & $12.12 \%$ \\
\hline
\end{tabular}

So, the final factor analysis was calculated, and it showed three clear factors. The components that emerged are reciprocity (positive or negative), willingness to give and trust. All three together explain $46.12 \%$ of the total variance. Thus, for the further analysis of the questionnaire, one question of each of the above-mentioned categories was selected. For the factor of reciprocity, two questions were selected and analyzed, one for positive and one for negative reciprocity.

\subsubsection{Analysis of the second part, main body of questions}

The following graphs illustrate the analysis of 4 questions, one for each category (see Graph 3, 4, 5 and 6 , below).

\section{Graph 3. The percentage of participants' responses to the concept of (positive) reciprocity}

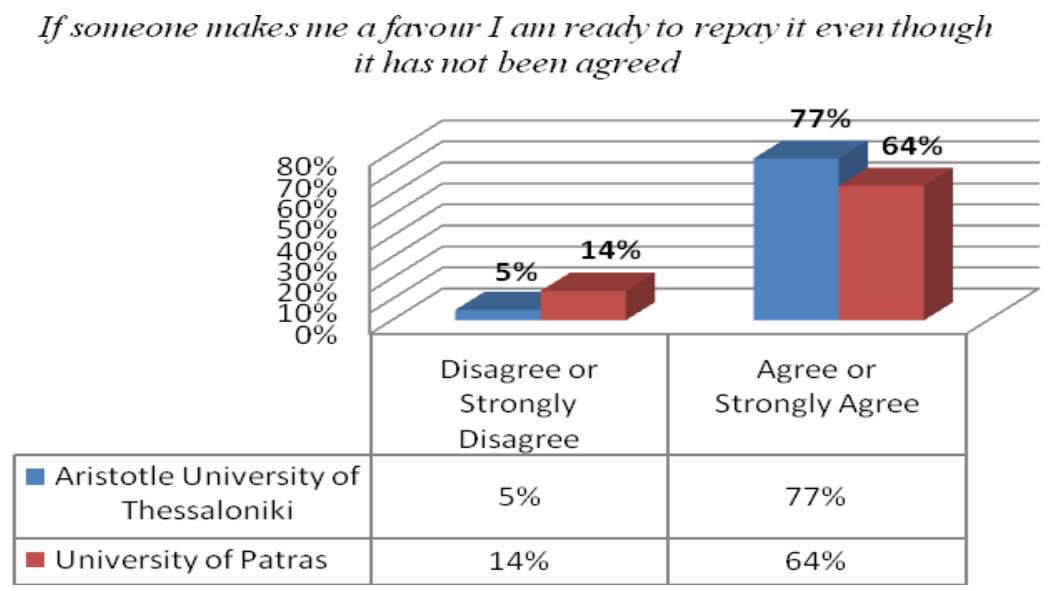

Source: Own calculations 
In both universities, nearly 7 out of 10 participants said that they were willing to respond with a corresponding kind of action to those who previously had introduced a similar. In this way, the students showed an unmistakable movement of positive reciprocity rejecting opportunism at the same time. However, according to an Independent-Samples $\mathrm{T}$ test, there is a statistically significant difference between the answers of the two samples. This is mainly due to the difference in positive responses, which is more than 10 percentage points. $(t=2.612, d f=197, p$ $=0.01<0.05$ ).

\section{Graph 4. The percentage of participants' responses to the concept of (negative) reciprocity}

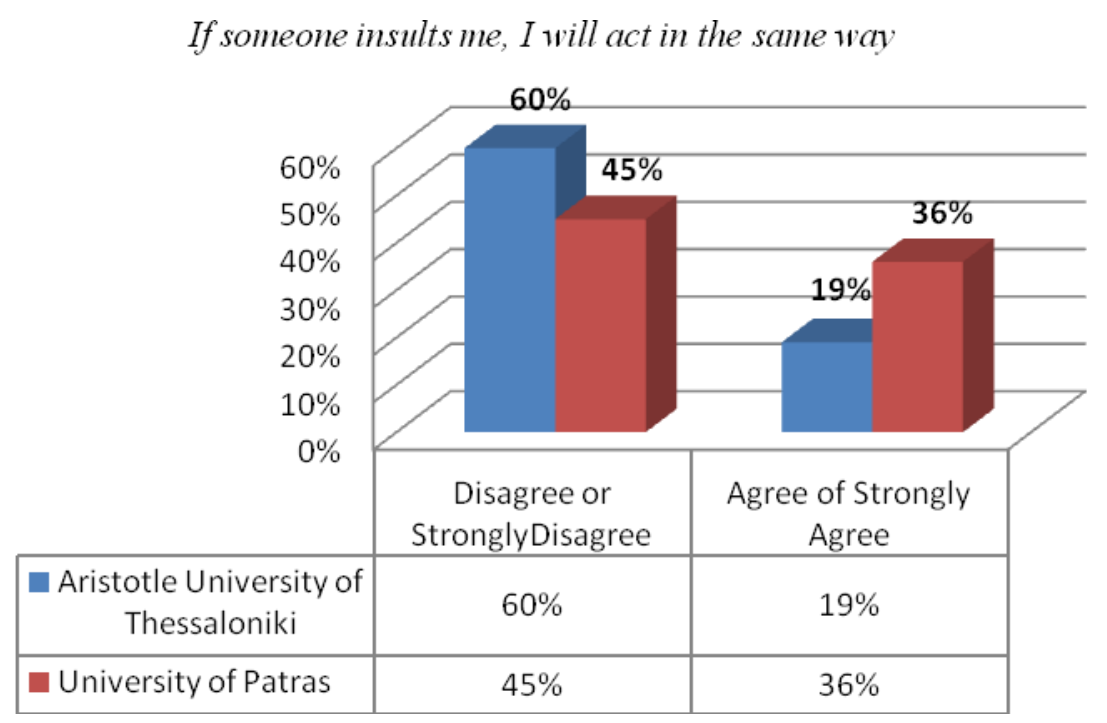

Source: Own calculations

As far as the above figure is concerned, $60 \%$ of students for the first sample and $45 \%$ of students for the second sample are not going to insult someone even if they have been insulted. If someone wants to be in full agreement with the norm of negative reciprocity then has to reciprocate the rude act to the other counterpart. Here, only $36 \%$ and $19 \%$ of the participants would react accordingly. In this way, the students oppose to the norm of negative reciprocity and thus disprove it. There is also a statistically significant difference between the two samples. ( $t=$ 2.55. $d f=197, p=0.012<0.05$ ). 


\section{Graph 5. The percentage of participants' responses to the concept of trust}

Most people try to take advantage of you if they have the opportunity.

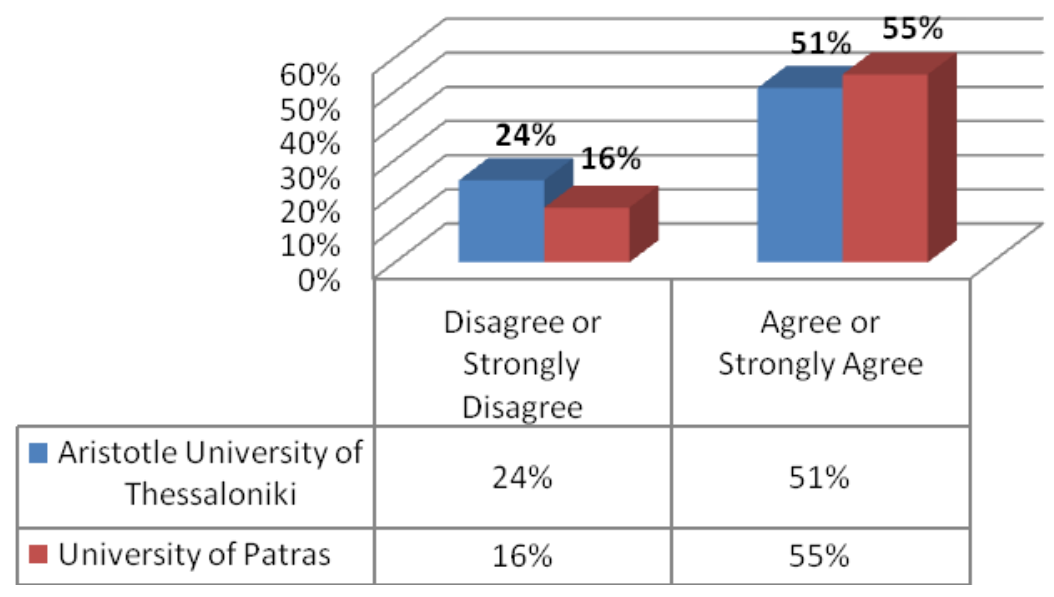

Source: Own calculations

Over the half of the participants in each case agree or stronlgy agree with the above statement (see Graph 5, above). Particularly, 51\% of students from Aristotle University of Thessaloniki and $56 \%$ of them from the University of Patras supported that. They believe that people will face you with a hostile manner if they have the opportunity to do so by not applying aspects such as justice, compassion and charity. In this case, the respondents' answers are similar, so there is no statistically significant difference. $(t=1.743, d f=198, p=0.083>0.05)$.

\section{Graph 6. The percentage of participants' responses to the concept of tipping.}

How often do you leave a tip (cafeteria, restaurant, bar etc)

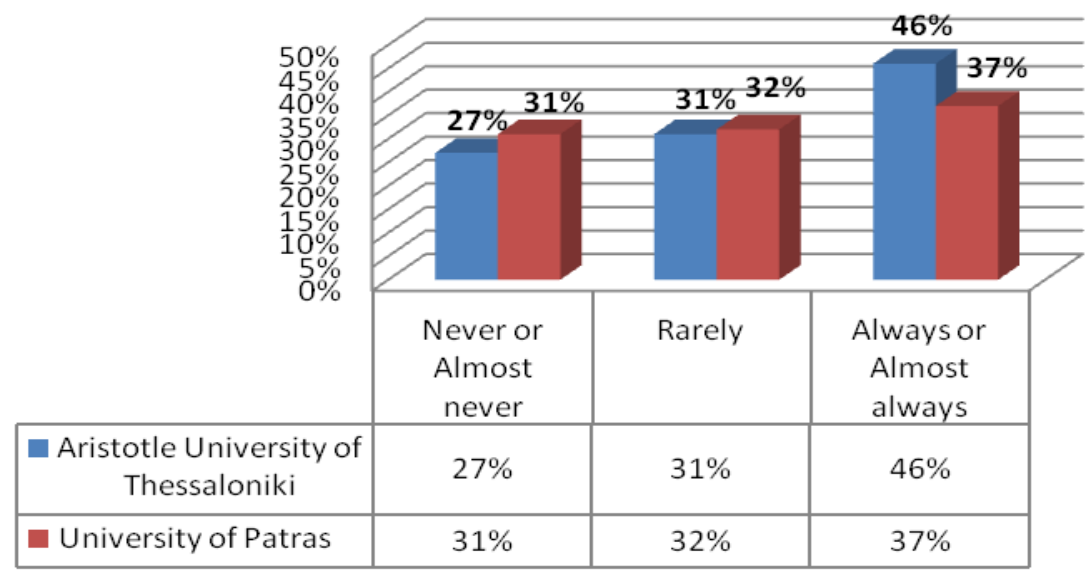

Source: Own calculations 
Only 3 out of 10 participants in both experimental procedures abide by the rational rule of economic behaviour and do not leave an amount of tip to people who serve them, i.e. individuals pay as much as the goods they receive. Another $30 \%$ of the students choose to leave tip but in rare cases. On the contrary, larger percentages accrue to the options "always or almost always" in both experiments with rates $46 \%$ and $37 \%$ respectively. This behavioural choice of individuals, i.e. to privilege those who have performed services for them with a monetary exchange, leads to a non-rational state since they prefer to minimize their income constraint to reward someone, rather than receive utility or satisfaction from buying something (see Graph 6). Restaurant tipping has been the subject of many recent empirical studies by scientists over the recent past. Parrett (2006), Azar (2010), Flynn and Greenberg (2011) also faced a similar behaviour in their experiments, a situation that confirms the aforementioned. In both of our experiments the answers of the participating students seem to be identical, since after the analysis of an Independent Samples T-test no statistically significant difference in their answers has emerged. ( $t$ $=0.887, d f=198, p=0.374>0.05)$.

\subsection{Experiments Analysis}

During the latter part of this work, that for the empirical measurement of reciprocity, the "Reciprocity Game" was designed and implemented among students in two Greek universities. To perform the two experimental procedures, all players had a not actual funding of $10 €$ while the sample numbered $(N=100)$ undergraduate students for each experiment, $(N=200)$ in total. During the experimental implementation of the games, the participants presented a variety of actions and reactions. The following graphs illustrate the moves and decisions of players both at the stage of first offer in the Ultimatum Game and the dictators' responses to the Dictator Game.

\subsubsection{Ultimatum Game Analysis}

In both experiments, $48 \%$ of the participating students decided to divide an equal offer, i.e. half of the available funding to the partner participant. Nevertheless, it is worth mentioning that there were students who made an anonymous allocation by offering more than half of the pot to the other parties with percentages to be $6 \%$ and $30 \%$, respectively for each university. On the contrary, 2.5 out of 10 students for Aristotle University and 2 out of 10 for the University of Patras proposed a division of less than $50 \%$ of the available cash (see Graph 7, bellow). According to the theory, the critical area of an allocation being rejected, varies between $30 \%$ and below of the total available amount. In these limits, the rates negotiated are $24 \%$ for the first sample and $8 \%$ for the second (see first two columns). 


\section{Graph 7. The Ultimatum Game}

The percentages of players' offers in the Ultimate Game

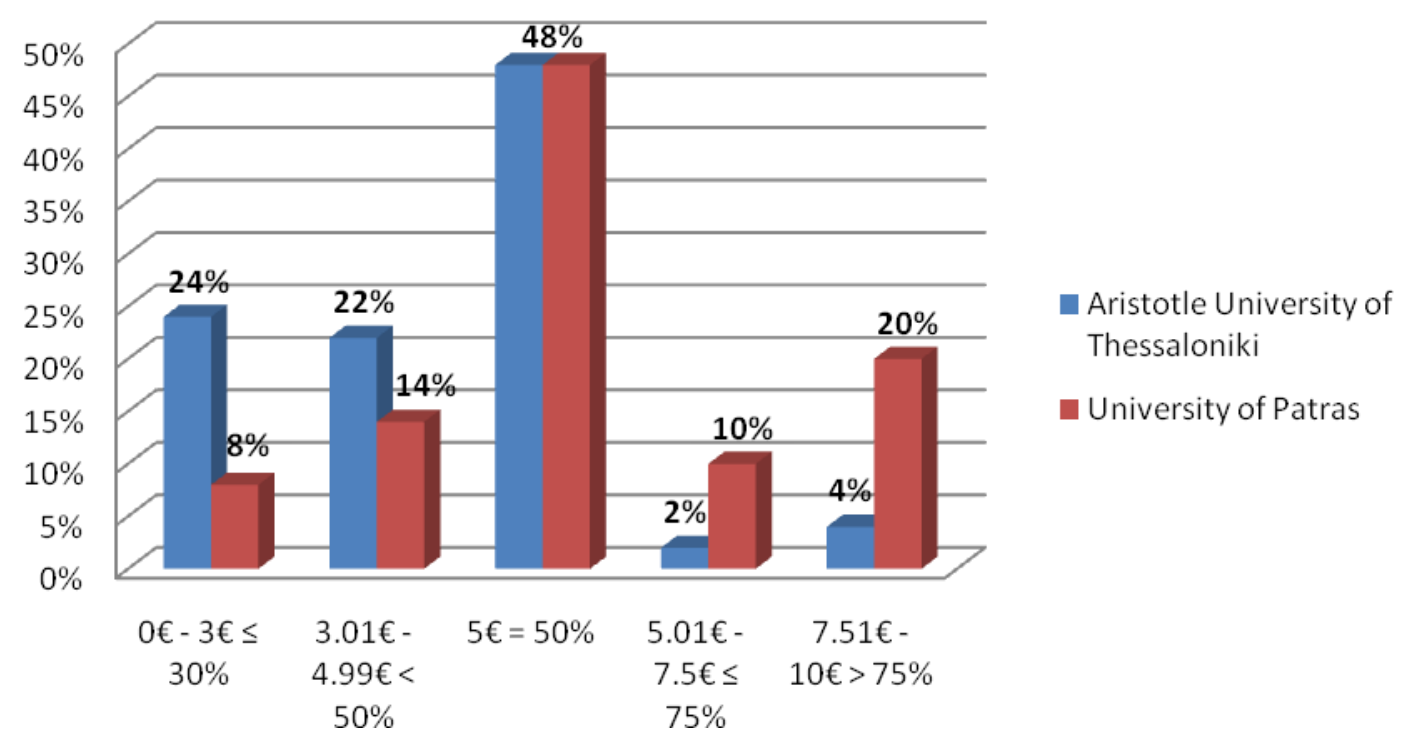

Source: Own calculations

At first glance and in accordance with offers recorded in the first scale of the experimental procedure, the subjects appeared to be possessed of generosity and equality while at the same time they sent a positive element for justice, trust and positive reciprocity to the opponent. With this behaviour, individuals essentially come to an absolute agreement with themselves, confirming under real circumstances the results of the first dichotomous question about fair and equal sharing between the two parties (see Graph 1, above). This people's behavioural attitude has already been confirmed worlwide from an increasing body of literature and findings from many empirical researches, too (Sonnegård, 1996; Taguchi, 2010; Rand et al., 2018).

Now, with respect to the graph below (see Grapgh 8), the acceptance percentages of the offers allocated reach $76 \%$ for the first experiment and $84 \%$ for the second experiment. However, $24 \%$ of the respondents from the first sample and $16 \%$ of the respondents from the second sample preferred to walk away with nothing, by rejecting the piece of the cake that they received, than to get something. This finding comes to a complete match with two previous indications. 


\section{Graph 8. The response of the second mover to the division received from the first player}

The percentages of the second movers'responses (Accept or Reject)

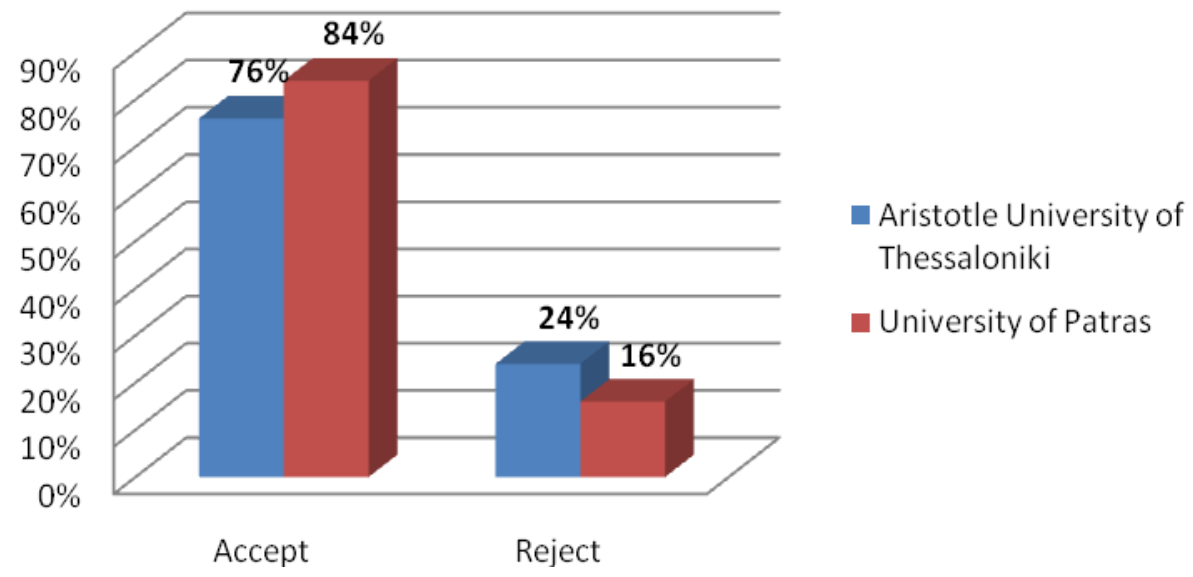

Source: Own calculations

First of all, both of the abovementioned percentages (24\% and $16 \%$ ), which are corresponded to the rejected offers, reflect the very low allocations, i.e. these below $30 \%$ of the amount of money is made available to the participants (see Graph 7). Secondly, the hypothetical second dichotomous question (see Graph 2) was also confirmed by experimental evidence, since the agents did not accept the very low-unfair, offers they received from the first players. In this way, they sustained and strengthened their original attitude both before (dichotomous question) and in realistic situations (experiment).

According to a literature review, not only do many empirical economists, but also the findings and conclusions exported from their lab and field surveys, indicate and support that extremely low offers, (not highest than $30 \%$ of the total quantity of money), even if they are positives, gather a high probability of being rejected and that is because the sense and emotion of inequality and injustice represent the individuals (Oosterbeek, Sloof and van de Kuilen, 2004; Knight, 2012; Zhang, 2013). On the other hand, some scientists have a different view. They claim that this behaviour of people instigates a kind of punishment towards the proposers in order to motivate them to make a more fair and equal offer (Levine 1998; Guala, 2012). Nevertheless, the selfcentered and rational theory defines the way a player must act in order to be a utility and profit maximizer differently. Conceptually, according to Singer (2010), the unique subgame perfect Nash equilibrium of the Ultimatum Game arises when subjects follow the following steps during the game.

- "Player 1 has to offer as little as possible (one euro, for example)".

- $\quad$ "Player 2 has to accept it because one euro is better than nothing." 


\subsubsection{Dictator Game Analysis}

In this game, both in the first experimental process (Aristotle University of Thessaloniki) and in the second experimental process (University of Patras), the "dictators" did not take advantage of their role in maximizing their utility and economic prosperity. So, instead of keeping the whole endowment for themselves, they rewarded the good offers received from the first players, while repaying justice, altruism and positive reciprocity to the other parts of the deal. Thus, the students failed to be adopted by the classical economic theory and be identified with a self-interest behaviour (see Graph 8, below).

\section{Graph 8. The Dictator Game}

The percentages of players' offers in the Dictator Game

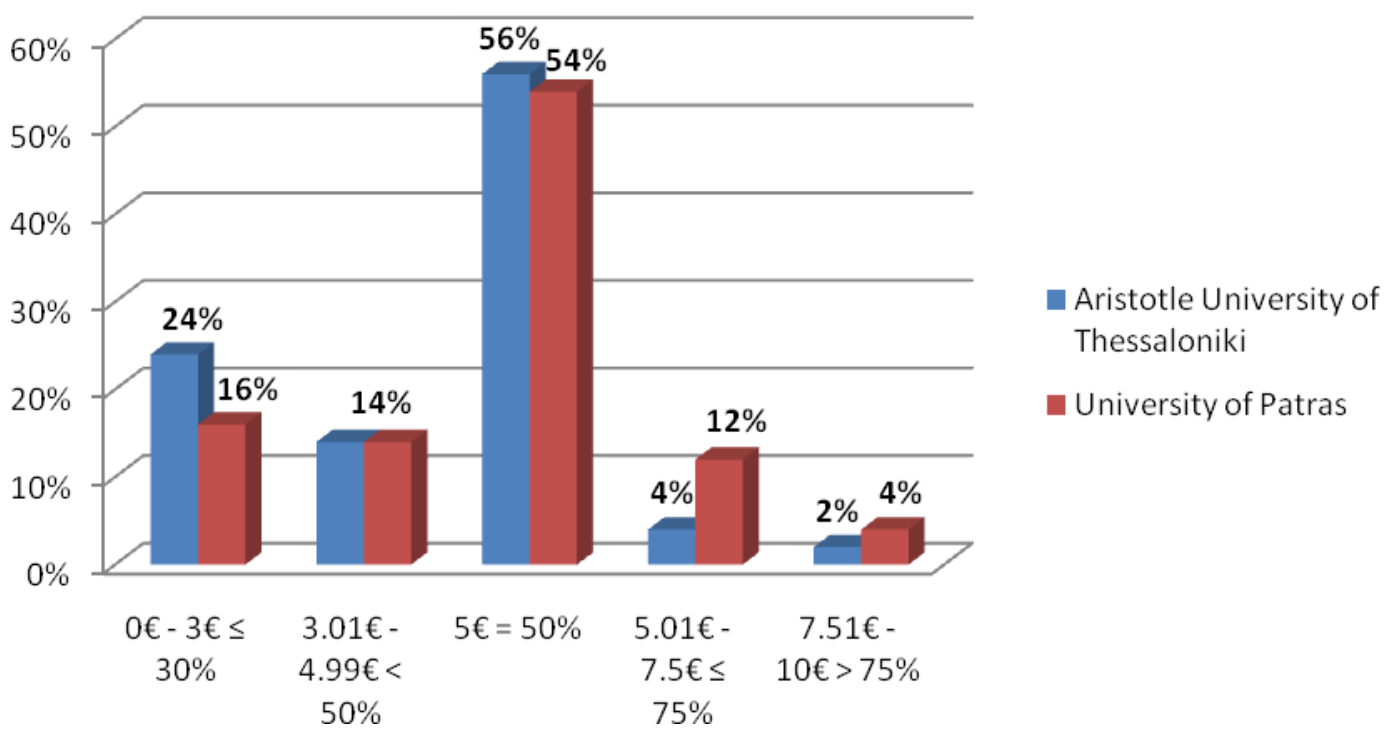

Source: Own calculations

In fact, the participants gave back, at over $50 \%$, the half of the available pie to the recipients, on each occasion. By acting like this, the second players behaved with the worthy feelings of justice, cooperation and reciprocity. Despite this, there was also a $24 \%$ rate for the first sample and a $16 \%$ rate for the second sample, which returned an offer equal or less than $30 \%$ of the available monetary units. However, these unfair offers can be justified and confirmed because their rates are exactly the same as those of the rejected offers received the dictators from the first players (see Graph 7).

To sum up, the majority of participating subjects involved in the role of the dictator in the Dictator Game responded to the good allocations they took during the round of the Ultimatum Game, repaid with equal divisions and behaved with a positive reciprocal behaviour, not wishing to gain from the dictator's role. This behaviour has been detected in a variety of research works under a variety of circumstances during the past (Eckel and Grossman, 1996; Engel, 2011). 


\section{Conclusions and Suggestions}

According to the experimental part of the survey, both the first sample and the second, participants distributed the amounts given to them equally, at a rate close to or above $50 \%$ of the sample, both in the Ultimatum and in the Dictator Game. This reciprocal behaviour refers to the altruistic students, working with self-denial. The empirical interactions of the participants are a very strong basis for creating an emotional statement on people's daily decision-making process but also a proof against the deeply rooted economic theory and its classical economic model of Homo Economicus. The deviation of the students from the rational-economic universe and the divergence from the model of the Homo Economicus was further strengthened in the round of the responses to the offers received. In this round the $24 \%$ for the first sample and the $16 \%$ for the second decided to reject the positive offers. This behaviour stands opposite to what Nashequilibrium defines for a rational behaviour while boost the existence of reciprocity in trades.

So, students in their trades showed a reciprocal behavour (positive or negative), proposed value allocations (equity and equality) both during the first and the second round of the game and in general identified with the reciprocal economic man, so-called Homo Reciprocans. In both universities, the sample of students demonstrated an emotional behaviour that externalized emotions such as equality, justice, altruism and reciprocity (positive or negative). Based on the results of the questionnaire, students in both universities desire an equitable and fair allocation and division, while at the same time they appeared negative in accepting an unfair offer, despite the fact that they would fail to maximize their expected utility and satisfaction so they would end up by getting nothing. At the same time students do not intend to offend someone even if they have been treated in a similar way before. Nevertheless, they think someone has to be careful before trusting other people. All these attitudes constitute the culmination of an irrational behaviour while they oppose to the Homo Economicus, the rational economic man, at least, at a theoretical stage, yet.

Despite the conclusions and the findings of this empirical paper, it is worth noting that it took place in a particular class of participants (students), in a limited age range (18-24 years) and with limited financial resources (hypothetical money). Therefore, for a future run of corresponding experiments, we suggest that it should be applied to a different collective group, like a political group, a voluntary group, a cooperative group or a sports team. Also, broader age limits would provide more complete and establish empirical evidence of people's behaviour and how they interact with others. 


\section{APPENDIX A: The Questionnaire used}

\begin{tabular}{ll} 
Q1 & In general, we can trust people \\
\hline Q2 & $\begin{array}{l}\text { If someone makes me a favour I am ready to repay it even } \\
\text { though it has not been agreed }\end{array}$ \\
\hline Q3 & $\begin{array}{l}\text { If I do something that will benefit someone else, then I expect } \\
\text { him to return my grace }\end{array}$ \\
\hline Q4 & $\begin{array}{l}\text { When I deal - negotiate - agree with strangers it is better to be } \\
\text { careful before I trust them }\end{array}$ \\
\hline Q5 & $\begin{array}{l}\text { Most people try to take advantage of you if they are given the } \\
\text { opportunity. }\end{array}$ \\
\hline Q6 & Most of the time people tend to be useful - helpful. \\
\hline Q7 & Nowadays, you cannot rely on somebody. \\
\hline Q8 & $\begin{array}{l}\text { If I suffer a serious wrong, I will take my revenge, no matter } \\
\text { what the costs }\end{array}$ \\
\hline Q9 & $\begin{array}{l}\text { If somebody puts me in a difficult position, I will do the same to } \\
\text { him/her }\end{array}$ \\
\hline Q10 & If someone insults me, I will act in the same way \\
\hline Q11 & $\begin{array}{l}\text { Do you lend personal belongings (CDs, books, bicycles, etc.) } \\
\text { to your friends? }\end{array}$ \\
\hline Q12 & Do you lend money to your friends? \\
\hline Q13 & How often do you leave a tip (cafeteria, restaurant, bar, etc)
\end{tabular}




\section{REFERENCES}

Avgeris, A., Kontogeorgos, A. and Sergaki, P. (2018). THE 'RECIPROCITY' GAME: A THEORETICAL BASIS FOR MEASURING RECIPROCITY IN HUMAN SOCIO-ECONOMIC INTERACTIONS. International Journal of Social Sciences, VII(1). https://doi.org/10.20472/ss2018.7.1.002

Avgeris, A., Kontogeorgos, A. and Sergaki, P. (2017). Reciprocity in trades: an experimental game approach. International Journal of Sustainable Agricultural Management and Informatics, 3(4), pp.298-313. https://doi.org/10.1504/ijsami.2017.090610

Axelrod, R. (1984). The evolution of cooperation. New York: Basic Books.

Azar, O. (2010). Do people tip because of psychological or strategic motivations? An empirical analysis of restaurant tipping. Applied Economics, 42(23), pp.3039-3044. https://doi.org/ 10.1080/00036840801964831

Beach, L. and Lipshitz, R. (1993). Why classical decision theory is an inappropriate standard for evaluating and aiding most human decision making. In: G. Klein, J. Orasanu, R. Caldenwood and C. Zsambok, ed., Decision making in action: Models and methods, 1st ed. Westport, CT: US: Ablex Publishing., pp.21-35.

Bernoulli, D. (1954). Exposition of a New Theory on the Measurement of Risk. Econometrica, 22(1), p.23. https://doi.org/10.2307/1909829

Bolton, G. and Ockenfels, A. (2000). ERC: A Theory of Equity, Reciprocity, and Competition. American Economic Review, 90(1), pp.166-193. https://doi.org/10.1257/aer.90.1.166

Bicskei, M., Lankau, M. and Bizer, K. (2016). Negative reciprocity and its relation to anger-like emotions in identity-homogeneous and -heterogeneous groups. Journal of Economic Psychology, 54, pp.1734. https://doi.org/10.1016/j.joep.2016.02.008

Camerer, C., Loewenstein, G. and Rabin, M. (2004). Advances in Behavioral Economics. 1st ed. Princeton and Oxford: Princeton University Press. https://doi.org/10.1515/9781400829118

Cartwright, E. (2014). Behavioral economics. 2nd ed. London \& New York: Routledge, pp.100-163. https://doi.org/10.4324/9780203816868

Charness, G. (2004). Attribution and Reciprocity in an Experimental Labor Market. Journal of Labor Economics, 22(3), pp.665-688. https://doi.org/10.1086/383111

Charness, G. and Rabin, M. (2002). Understanding Social Preferences with Simple Tests. The Quarterly Journal of Economics, 117(3), pp.817-869. https://doi.org/10.1162/003355302760193904

Cosmides, L. and Tooby, J. (1989). Evolutionary psychology and the generation of culture, part II. Ethology and Sociobiology, 10(1-3), pp.51-97. https://doi.org/10.1016/0162-3095(89)90013-7

Cox, J., Friedman, D. and Gjerstad, S. (2007). A tractable model of reciprocity and fairness. Games and Economic Behavior, 59(1), pp.17-45. https://doi.org/10.1016/j.geb.2006.05.001

de Waal, F. B. M. and Berger L. B. (2000). Payment for Labor in Monkeys. Nature, 404(6778), p.563. https://doi.org/10.1038/35007138

Dufwenberg, M. and Kirchsteiger, G. (2004). A theory of sequential reciprocity. Games and Economic Behavior, 47(2), pp.268-298. https://doi.org/10.1016/j.geb.2003.06.003

Eckel, C. and Grossman, P. (1996). Altruism in Anonymous Dictator Games. Games and Economic Behavior, 16(2), pp.181-191. https://doi.org/10.1006/game.1996.0081

Engel, C. (2011). Dictator games: a meta study. Experimental Economics, 14(4), pp.583-610. https://doi.org/10.1007/s10683-011-9283-7

Engle-Warnick, J. and Mishagina, N. (2014). Insensitivity to Prices in a Dictator Game. SSRN Electronic Journal. https://doi.org/10.2139/ssrn.2403953

Falk, A., Fehr, E. and Fischbacher, U. (2008). Testing theories of fairness-Intentions matter. Games and Economic Behavior, 62(1), pp.287-303. https://doi.org/10.1016/j.geb.2007.06.001 
Falk, A. and Fischbacher, U. (2006). A theory of reciprocity. Games and Economic Behavior, 54(2), pp.293-315. https://doi.org/10.1016/j.geb.2005.03.001

Fehr, E. and Gächter, S. (2000). Fairness and Retaliation: The Economics of Reciprocity. Journal of Economic Perspectives, 14(3), pp.159-182. https://doi.org/10.1257/jep.14.3.159

Fehr, E., Kirchsteiger, G. and Riedl, A. (1998). Gift exchange and reciprocity in competitive experimental markets. European Economic Review, 42(1), pp.1-34. . https://doi.org/10.1016/s00142921(96)00051-7

Fehr, E. and Scmidt, K. (2006). The Economics of Fairness, Reciprocity and Altruism - Experimental Evidence and New Theories. In: S. Kolm and M. Mercier Ythier, ed., Handbook of the Economics of Giving, Altruism and Reciprocity. Amsterdam: North Holland Publication Co, pp.615-691. https://doi.org/10.1016/S1574-0714(06)01008-6

FLYNN, S. and GREENBERG, A. (2011). Does Weather Actually Affect Tipping? An Empirical Analysis of Time-Series Data1. Journal of Applied Social Psychology, 42(3), pp.702-716. https://doi.org/ 10.1111/j.1559-1816.2011.00813.x

Geanakoplos, J., Pearce, D. and Stacchetti, E. (1989). Psychological games and sequential rationality. Games and Economic Behavior, 1(1), pp.60-79. https://doi.org/10.1016/08998256(89)90005-5

Goodwin, N., Harris, J., Nelson, J., Roach, B., Torras, M., Ackerman, F. and Weisskopf, T. (2013). Economic Behavior and Rationality. In: N. Goodwin, J. Nelson, J. Harris, B. Roach and M. Torras, ed., Microeconomics in Context, 3rd ed. M.E. Sharpe, pp.145-157.

Guala, F. (2012). Reciprocity: Weak or strong? What punishment experiments do (and do not) demonstrate. Behavioral and Brain Sciences, 35(01), pp.1-15. https://doi.org/10.1017/s0140525×11000069

Gutnik, L., Hakimzada, A., Yoskowitz, N. and Patel, V. (2006). The role of emotion in decision-making: A cognitive neuroeconomic approach towards understanding sexual risk behavior. Journal of Biomedical Informatics, 39(6), pp.720-736. https://doi.org/10.1016/j.jbi.2006.03.002

Güth, W., Schmittberger, R. and Schwarze, B. (1982). An experimental analysis of ultimatum bargaining. Journal of Economic Behavior \& Organization, 3(4), pp.367-388. https://doi.org/10.1016/0167-2681(82)90011-7

Harrison, E. (1993). Interdisciplinary Models of Decision Making. Management Decision, 31(8). https://doi.org/10.1108/00251749310047124

Hastie, R. and Dawes, R. (2010). Rational choice in an uncertain world. London: SAGE.

Heracleous, L. (1994). Rational Decision Making: Myth or Reality?. Management Development Review, 7(4), pp.16-23. https://doi.org/10.1108/09622519410771628

Jensen, K., Call, J. and Tomasello, M. (2007). Chimpanzees Are Rational Maximizers in an Ultimatum Game. Science, 318(5847), pp.107-109. https://doi.org/10.1126/science.1145850

Kahneman, D., Knetsch, J. and Thaler, R. (1986). Fairness and the Assumptions of Economics. The Journal of Business, 59(4), pp.285-300. https://doi.org/10.1086/296367

Kaltwasser, L., Hildebrandt, A., Wilhelm, O. and Sommer, W. (2016). Behavioral and neuronal determinants of negative reciprocity in the ultimatum game. Social Cognitive and Affective Neuroscience, 11(10), pp.1608-1617. https://doi.org10.1093/scan/nsw069

Keohane, R. (1986). Reciprocity in International Relations. International Organization, 40(1), pp.1-27. https://doi.org/10.1017/S0020818300004458

Komorita, S. and Parks, C. (1999). Reciprocity and cooperation in social dilemmas: review and future directions. In: D. Budescu, I. Erev and R. Zwick, ed., Games and Human Behavior: Essays in Honor of Amnon Rapoport. Mahwah, NJ, US: Lawrence Erlbaum Associates Publishers, pp.315-330.

Knight, S. (2012). Fairness or anger in ultimatum game rejections?. Journal of European Psychology Students, 3(1), pp.2-14. http://doi.org/10.5334/jeps.an 
Krupka, E. and Weber, R. (2013). IDENTIFYING SOCIAL NORMS USING COORDINATION GAMES: WHY DOES DICTATOR GAME SHARING VARY?. Journal of the European Economic Association, 11(3), pp.495-524. https://doi.org/10.1111/jeea.12006

Levine, D. (1998). Modeling Altruism and Spitefulness in Experiments. Review of Economic Dynamics, 1(3), pp.593-622. https://doi.org/10.1006/redy.1998.0023

Loewenstein, G. and Lerner, J. (2003). The role of affect in decision making. In: R. Davidson, H. Goldsmith and K. Scherer, ed., Handbook of Affective Science, 1st ed. Oxford: Oxford University Press., pp.619-642.

Maximiano, S. (2012). Measuring reciprocity: Do survey and experimental data correlate?. Working Paper. Prurdue University - Department of Economics - Krannert School of Management.

McCabe, K., Rigdon, M. and Smith, V. (2003). Positive reciprocity and intentions in trust games. Journal of Economic Behavior \& Organization, 52(2), pp.267-275. https://doi.org/10.1016/s01672681(03)00003-9

Neumann, T., Kierspel, S., Windrich, I., Berger, R. and Vogt, B. (2018). How to Split Gains and Losses? Experimental Evidence of Dictator and Ultimatum Games. Games, 9(4), p.78. https://doi.org/10.3390/g9040078

Nowak, M. and Sigmund, K. (1998). Evolution of indirect reciprocity by image scoring. Nature, 393(6685), pp.573-577. https://doi.org/10.1038/31225

Oberholzer-Gee, F. and Eichenberger, R. (2008). Fairness in Extended Dictator Game Experiments. The B.E. Journal of Economic Analysis \& Policy, 8(1). https://doi.org/10.2202/19351682.1718

Oosterbeek, H., Sloof, R. and van de Kuilen, G. (2004). Cultural Differences in Ultimatum Game Experiments: Evidence from a Meta-Analysis. Experimental Economics, 7(2), pp.171-188. https://doi.org/10.1023/b:exec.0000026978.14316.74

PAGE, K. and NOWAK, M. (2001). A Generalized Adaptive Dynamics Framework can Describe the Evolutionary Ultimatum Game. Journal of Theoretical Biology, 209(2), pp.173-179. https://doi.org/10.1006/jtbi.2000.2251

Panas, E. (2007). Experimental Economics: An Empirical Analysis. SPOUDAl, 83(2), pp.89-105.

Parrett, M. (2006). An Analysis of the Determinants of Tipping Behavior: A Laboratory Experiment and Evidence from Restaurant Tipping. Southern Economic Journal, 73(2), p.489-514. https://doi.org/ $10.2307 / 20111903$

Perugini, M., Gallucci, M., Presaghi, F. and Ercolani, A. (2003). The personal norm of reciprocity. European Journal of Personality, 17(4), pp.251-283. https://doi.org/10.1002/per.474

Proctor, D., Brosnan, S. and de Waal, F. (2013). How fairly do chimpanzees play the ultimatum game?. Communicative \& Integrative Biology, 6(3), p.e23819. https://doi.org/ 10.4161/cib.23819

Prüfer, K., Munch, K., Hellmann, I., Akagi, K., Miller, J., Walenz, B., Koren, S., Sutton, G., Kodira, C., Winer, R., Knight, J., Mullikin, J., Meader, S., Ponting, C., Lunter, G., Higashino, S., Hobolth, A., Dutheil, J., Karakoç, E., Alkan, C., Sajjadian, S., Catacchio, C., Ventura, M., Marques-Bonet, T., Eichler, E., André, C., Atencia, R., Mugisha, L., Junhold, J., Patterson, N., Siebauer, M., Good, J., Fischer, A., Ptak, S., Lachmann, M., Symer, D., Mailund, T., Schierup, M., Andrés, A., Kelso, J. and Pääbo, S. (2012). The bonobo genome compared with the chimpanzee and human genomes. Nature, 486(7404), pp.527-531. https://doi.org/10.1038/nature11128

Rabin, M. (1993). Incorporating fairness into game theory and economics. The American Economic Review, 83(5), pp. 1281-1302.

Rand, D., Tarnita, C., Ohtsuki, H. and Nowak, M. (2018). Evolution of fairness in the one-shot anonymous Ultimatum Game. PNAS, 110(7), pp.2581-2586. https://doi.org/10.1073/pnas.1214167110 
Rauhut, H. and Winter, F. (2010). A sociological perspective on measuring social norms by means of strategy method experiments. Social Science Research, 39(6), pp.1181-1194. https://doi.org/10.1016/j.ssresearch.2010.06.009

Restubog, S., Garcia, P., Wang, L. and Cheng, D. (2010). It's all about control: The role of self-control in buffering the effects of negative reciprocity beliefs and trait anger on workplace deviance. Journal of Research in Personality, 44(5), pp.655-660. https://doi.org/10.1016/j.jrp.2010.06.007

Rietz, T., Schniter, E., Sheremeta, R. and Shields, T. (2017). TRUST, RECIPROCITY, AND RULES. Economic Inquiry, 56(3), pp.1526-1542. https://doi.org/10.1111/ecin.12512

Segal, U. and Sobel, J. (2007). Tit for tat: Foundations of preferences for reciprocity in strategic settings. Journal of Economic Theory, 136(1), pp.197-216. https://doi.org/10.1016/j.jet.2006.07.003

Shen, J. and Takahashi, H. (2013). A cash effect in ultimatum game experiments. The Journal of SocioEconomics, 47, pp.94-102. https://doi.org/10.1016/j.socec.2013.09.005

Sobel, J. (2005). Interdependent Preferences and Reciprocity. Journal of Economic Literature, 43(2), pp.392-436. https://doi.org/10.1257/0022051054661530

Solnick, S. and Schweitzer, M. (1999). The Influence of Physical Attractiveness and Gender on Ultimatum Game Decisions. Organizational Behavior and Human Decision Processes, 79(3), pp.199215. https://doi.org/10.1006/obhd.1999.2843

Sonnegård, J. (1996). Determination of first movers in sequential bargaining games: An experimental study. Journal of Economic Psychology, 17(3), pp.359-386. https://doi.org/10.1016/01674870(96)00014-1

Stanca, L., Bruni, L. and Corazzini, L. (2009). Testing theories of reciprocity: Do motivations matter?. Journal of Economic Behavior \& Organization, 71(2), pp.233-245. https://doi.org/10.1016/j.jebo.2009.04.009

Taguchi, S. (2010). An Experimental Study on Presentation Format Effect of Income Statement: Evidence from a Modified Ultimatum Bargaining Game Experiment. SSRN Electronic Journal. https://doi.org/10.2139/ssrn.1546915

Trivers, R. (1971). The evolution of reciprocal altruism. Quarterly Review of Biology, 46(1), pp.35-57. https://doi.org/10.1086/406755

Tversky, A. (1982). Remarks on the Study of Decision Making. In: G. Ungson, ed., Decision making: An interdisciplinary inquiry, 1st ed. Boston, Mass: Kent Pub. Co, p.321.

Wedekind, C. (2000). Cooperation Through Image Scoring in Humans. Science, 288(5467), pp.850-852. https://doi.org/10.1126/science.288.5467.850

Wu, L., Zhang, H., Chiu, R., Kwan, H. and He, X. (2013). Hostile Attribution Bias and Negative Reciprocity Beliefs Exacerbate Incivility's Effects on Interpersonal Deviance. Journal of Business Ethics, 120(2), pp.189-199. https://doi.org/10.1007/s10551-013-1658-6

Zhang, B. (2013). Social Learning in the Ultimatum Game. PLoS ONE, 8(9). https://doi.org/10.1371/journal.pone.0074540 